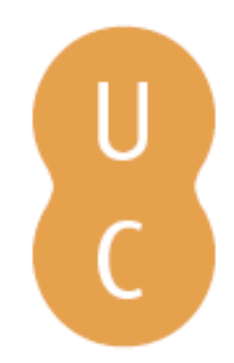

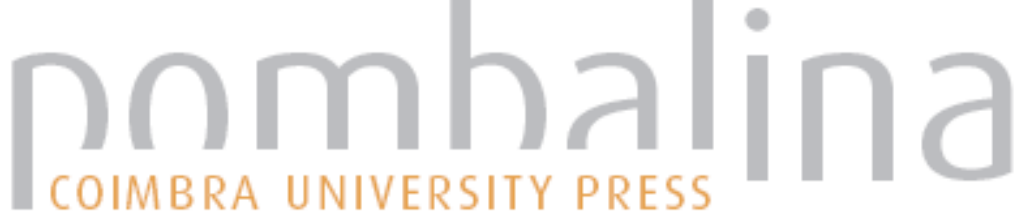

Os partos distócicos em Amato Lusitano e em Rodrigo de Castro: fontes, doutrinas e terapias greco-romanas
Autor(es):
Pinheiro, Cristina Santos
Publicado por: UA Editora - Universidade de Aveiro; Imprensa da Universidade de
URL persistente:
Coimbra; Annablume
DOI:
URI:http://hdl.handle.net/10316.2/35700
DOl:http://dx.doi.org/10.14195/978-989-26-0941-6_14
Accessed : $\quad$ 26-Apr-2023 08:58:17

A navegação consulta e descarregamento dos títulos inseridos nas Bibliotecas Digitais UC Digitalis, UC Pombalina e UC Impactum, pressupõem a aceitação plena e sem reservas dos Termos e Condições de Uso destas Bibliotecas Digitais, disponíveis em https://digitalis.uc.pt/pt-pt/termos.

Conforme exposto nos referidos Termos e Condições de Uso, o descarregamento de títulos de acesso restrito requer uma licença válida de autorização devendo o utilizador aceder ao(s) documento(s) a partir de um endereço de IP da instituição detentora da supramencionada licença.

Ao utilizador é apenas permitido o descarregamento para uso pessoal, pelo que o emprego do(s) título(s) descarregado(s) para outro fim, designadamente comercial, carece de autorização do respetivo autor ou editor da obra.

Na medida em que todas as obras da UC Digitalis se encontram protegidas pelo Código do Direito de Autor e Direitos Conexos e demais legislação aplicável, toda a cópia, parcial ou total, deste documento, nos casos em que é legalmente admitida, deverá conter ou fazer-se acompanhar por este aviso.

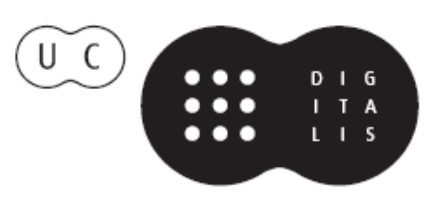




\section{HUMANISMO E CIÊNCIA Antiguidade e Renascimento}

António Manuel Lopes Andrade

Carlos de Miguel Mora

João Manuel Nunes Torrão
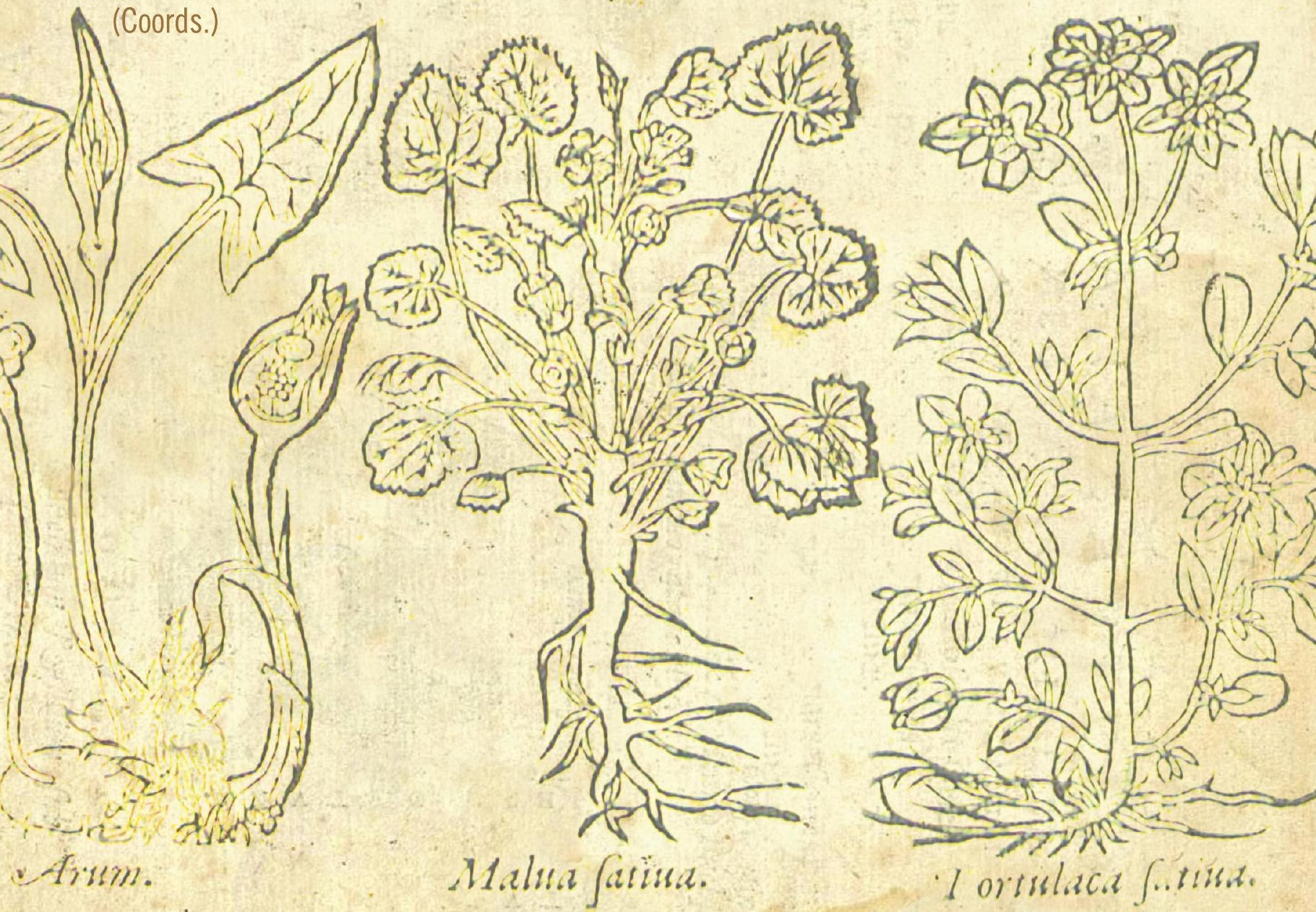

Aveiro I Coimbra I São Paulo 2015

UA Editora - Universidade de Aveiro I Imprensa da Universidade de Coimbra I Annablume 
Este volume resulta de várias iniciativas desenvolvidas no âmbito do projecto de I\&D "Dioscórides e o Humanismo Português: os Comentários de Amato Lusitano" (http://amatolusitano.web.ua.pt), recoIhendo contribuições de mais de duas dezenas de colaboradores, tanto de membros da equipa como de outros investigadores nacionais e estrangeiros. Entre os eventos que estiveram na origem deste livro destacam-se as três edições do Ciclo de Conferências promovido pelo projecto, realizadas entre 2010 e 2013, e sobretudo o Colóquio Internacional "Dioscórides e o Humanismo Português: os Comentários de Amato Lusitano", que decorreu no Departamento de Línguas e Culturas da Universidade de Aveiro, nos dias 21 e 22 de Novembro de 2013.

0 objectivo principal do projecto é a edição e tradução para português dos dois livros que Amato Lusitano dedicou ao comentário do tratado grego De materia medica de Dioscórides, ou seja, o Index Dioscoridis (Antuérpia, 1536) e as In Dioscoridlis Anazarbei de medica materia libros quinque... enarrationes (Veneza, 1553), estando contemplada, também, a tradução de mais duas obras directamente correlacionadas com os livros do médico português: a montante, a do próprio tratado grego de Dioscórides; a jusante, a do livro intitulado Apologia adversus Amathum Lusitanum (Veneza, 1558) de Pietro Andrea Mattioli.

OBRA PUBLICADA COM A COORDENAÇÃO

CIENTÍFICA DE:

Centro de Línguas, Literaturas e Culturas da Universidade de Aveiro

Centro de Estudos Clássicos e Humanísticos da Universidade de Coimbra

Cátedra de Estudos Sefarditas "Alberto

Benveniste" da Faculdade de Letras da Universidade de Lisboa 


\section{HUMANISMO E CIÊNCIA}

\section{Antiguidade e Renascimento}

ANTÓNIO MANUEL LOPES ANDRADE

CARLOS DE MIGUEL MORA

JOÃO MANUEL NUNES TORRÃO

(COORDS.)

AVEIRO • COIMBRA • SÃO PAULO

2015

UA EDITORA • UNIVERSIDADE DE AVEIRO

IMPRENSA DA UNIVERSIDADE DE COIMBRA

ANNABLUME 


\section{HUMANISMO E CIÊNCIA: Antiguidade e Renascimento}

\author{
EDIÇÃO

UA EDITORA • UNIVERSIDADE DE AVEIRO
IMPRENSA DA UNIVERSIDADE DE COIMBRA
ANNABLUME

ORGANIZAÇÃO E COORDENAÇÃO EDITORIAL ANTÓNIO MANUEL LOPES ANDRADE

CARLOS DE MIGUEL MORA

JOÃO MANUEL NUNES TORRÃO

\author{
DESIGN DA CAPA \\ MEIOKILO DESIGN STUDIO
}

DESIGN

CARLOS COSTA

IMPRESSÃO E ACABAMENTO

SERSILITO • MAIA

ISBN

UA • 978-972-789-434-5

IUC • 978-989-26-0940-9

\section{ISBN DIGITAL}

UA • 978-972-789-435-2

IUC • 978-989-26-0941-6

DOI

http://dx.doi.org/10.14195/ 978-989-26-0941-6

DEPÓSITO LEGAL 368241/13

TIRAGEM 500 Exemplares

(C) 2015

UA EDITORA • UNIVERSIDADE DE AVEIRO IMPRENSA DA UNIVERSIDADE DE COIMBRA

ANNABLUME

\section{COMISSÃO CIENTÍFICA}

António Manuel Lopes Andrade

Carlos de Miguel Mora

Delfim Ferreira Leão

Henrique Leitão

João Manuel Nunes Torrão

Maria de Fátima Reis

Maria do Céu Zambujo Fialho

Miguel Ángel González Manjarrés

\section{TEXTOS}

Adelino Cardoso

Ana Leonor Pereira

Ana Margarida Borges

António Guimarães Pinto

António Maria Martins Melo

Bernardo Mota

Carlos A. Martins de Jesus

Carlos de Miguel Mora

Cristina Santos Pinheiro

Donald Beecher

Emília Oliveira

Isabel Malaquias

James W. Nelson Novoa

Joana Mestre Costa

João Manuel Nunes Torrão

João Rui Pita

Jorge Paiva

José Sílvio Moreira Fernandes

Maria de Fátima Silva

Miguel Ángel González Manjarrés

Rui Manuel Loureiro

Telmo Corujo dos Reis

Teresa Nobre de Carvalho

Vinicije B. Lupis

Virgínia Soares Pereira 


\section{HUMANISMO E CIÊNCIA}

\section{Antiguidade e Renascimento}

ANTÓNIO MANUEL LOPES ANDRADE

CARLOS DE MIGUEL MORA

JOÃO MANUEL NUNES TORRÃO

(COORDS.)

AVEIRO • COIMBRA • SÃO PAULO

2015

UA EDITORA • UNIVERSIDADE DE AVEIRO

IMPRENSA DA UNIVERSIDADE DE COIMBRA

ANNABLUME 
OBRA PUBLICADA

COM A COORDENAÇÃO

CIENTÍFICA DE:

CENTRO DE LÍNGUAS,

LITERATURAS E CULTURAS DA

UNIVERSIDADE DE AVEIRO

CENTRO DE ESTUDOS

CLÁSSICOS E HUMANÍSTICOS DA

UNIVERSIDADE DE COIMBRA

CÁTEDRA DE ESTUDOS SEFARDITAS

"ALBERTO BENVENISTE"

DA FACULDADE DE LETRAS DA

UNIVERSIDADE DE LISBOA 


\section{SUMÁRIO}

PREFÁCIO

1.1 "Teofrasto, Tratado das plantas. No alvor de uma nova ciência" 13

Maria de Fátima Silva

1.2 "Francisco de Melo e os fragmentos de teoria óptica de Pierre Brissot" 21 Bernardo Mota

1.3 "Algumas reflexões sobre as pedras preciosas nos Colóquios dos simples de Garcia de Orta" 37 Rui Manuel Loureiro

1.4 "Estratégias, patronos e favores em Colóquios dos Simples de Garcia de Orta" 63 Teresa Nobre de Carvalho

1.5 "As plantas na obra poética de Camões (épica e lírica)" 95 Jorge Paiva

1.6 "Nicolás Monardes, John Frampton and the Medical Wonders of the New World" .141 Donald Beecher

1.7 "Literatura e Medicina: alguns textos de Justo Lípsio e de dois doutores Luís Nunes" 161 António Guimarães Pinto

1.8 "Ontologias e idiossincrasias dos Amantes, à luz da Archipathologia de Filipe Montalto" ...... 211 Joana Mestre Costa \& Adelino Cardoso

1.9 "Gabriel da Fonseca. A New Christian doctor in Bernini's Rome". .227 James W. Nelson Novoa 


\section{2) DIOSCÓRIDES E O HUMANISMO PORTUGUÊS: OS COMENTÁRIOS DE AMATO LUSITANO}

2.1 "Léxico científico português nos Comentários de Amato: antecedentes e receção"

Ana Margarida Borges

2.2 "Usos medicinais das plantas, em Amato Lusitano: o bálsamo"

António Maria Martins Melo

2.3 "Amato Lusitano e a importância da ilustração botânica no século xVI.

Em torno das edições lionesas das Enarrationes (1558)"

Carlos A. Martins de Jesus

2.4 "Sobre la identificación entre ébano y guayaco en una entrada

del Index Dioscoridis de Amato Lusitano".

Carlos de Miguel Mora

2.5 "Os partos distócicos em Amato Lusitano e em Rodrigo de Castro:

fontes, doutrinas e terapias greco-romanas"

\section{Cristina Santos Pinheiro}

2.6 "Do carvalho ao castanheiro: usos e propriedades medicinais

de fagáceas nas Enarrationes de Amato Lusitano".

Emília Oliveira

2.7 "O mundo mineral nos Comentários a Dioscórides de Amato Lusitano".

Isabel Malaquias \& Virgínia Soares Pereira

2.8 "Alguns comentários de Amato: entre a estranheza e a realidade"

João Manuel Nunes Torrão

2.9 "Caracterização e usos terapêuticos de produtos de origem marinha

nos Comentários de Amato Lusitano a Dioscórides"

José Sílvio Moreira Fernandes

2.10 "La mandrágora de Amato Lusitano: edición, traducción y anotación"

Miguel Ángel González Manjarrés

2.11 "O vinho e os vinhos - usos e virtudes de um dom dos deuses

nas Enarrationes de Amato Lusitano"

Telmo Corujo dos Reis

2.12 "Amatus Lusitanus e Didaco Pirro: due ebrei portoghesi

e cerchia umanistica di Dubrovnik" 481

Vinicije B. Lupis

2.13 "Estudos contemporâneos sobre Amato Lusitano". 513

João Rui Pita \& Ana Leonor Pereira 


\title{
Os partos distócicos em Amato Lusitano e em Rodrigo de Castro: fontes, doutrinas e terapias greco-romanas
}

CRISTINA SANTOS PINHEIRO ${ }^{1}$

\section{RESUMO:}

Configurando-se tradicionalmente o parto como um acontecimento conduzido por parteiras, em que só excepcionalmente e perante dificuldades extremas se apelava a um médico, nos casos em que ambos estavam presentes manifestava-se uma distinção fundamental entre as práticas médicas utilizadas por uns e outros. Tendo esta divergência em mente, analisamos nas Curationum medicinalium centuriae de Amato Lusitano e no De universa mulierum medicina de Rodrigo de Castro Lusitano, as fontes gregas e romanas que os autores referem ao descreverem os partos distócicos - em especial, os tratados hipocráticos De mulierum affectibus e De superfetatione e os Gynaikeia de Sorano - e como o discurso de ambos reforça a importância do saber médico no contexto das dificuldades que é forçoso enfrentar nestas circunstâncias.

\section{PALAVRAS-CHAVE:}

História da Medicina; textos de ginecologia; medicina renascentista; obstetrícia; ginecologia.

\begin{abstract}
:
By tradition, childbirth was an event conducted by midwives, when only exceptionally and in face of extreme difficulties a doctor was called for. When the midwife and the doctor attended, a fundamental distinction emerged between the medical practices used by one and by the other. Having this difference in mind, we analyze in Amatus Lusitanus' Curationum medicinalium centuriae and in Rodericus a Castro Lusitanus' De universa mulierum medicina the Greek and Roman sources that the authors use to treat dystocia - in particular, the Hippocratic treatises De mulierum affectibus and De superfetatione, as well as Soranos' Gynaikeia - and how the discourse of these authors reinforces the importance of medical knowledge in the context of the difficulties they must face under these circumstances.
\end{abstract}

\section{KEYWORDS:}

history of medicine; gynaecological texts; Early Modern medicine; obstetrics; gynaecology.

1 Universidade da Madeira; Centro de Estudos Clássicos da Universidade de Lisboa: polybios@uma.pt. 
As dificuldades que podiam surgir no decorrer do nascimento de uma criança são tema de exposições detalhadas nos textos gregos e romanos sobre medicina. Já no Corpo Hipocrático ${ }^{2}$, as referências a fetos mortos ou em posição anormal in utero e a substâncias e técnicas que

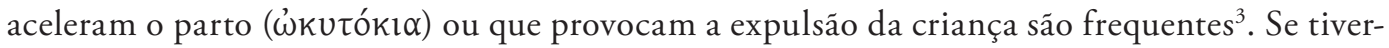
mos igualmente em consideração o pormenor com que se descrevem intervençóes cirúrgicas como a que tinha como finalidade desmembrar e extrair do ventre materno, parte por parte, um feto morto ou inviável, podemos com alguma legitimidade concluir que se tratava de uma situação frequente, que permitiu o desenvolvimento de um conjunto mais ou menos consistente de técnicas e saberes. Nestas ocasióes, em que, por alguma razão, o parto não se desenrolava

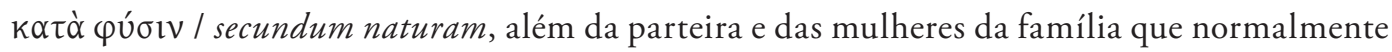
prestavam assistência, apelava-se ao médico.

Nancy Demand considera que no século V a. C. os autores dos tratados hipocráticos de ginecologia retiraram do domínio exclusivo das mulheres as questóes médicas relacionadas com a gravidez e o parto: «(...) childbirth was medicalized, and male doctors came to exercise a degree of control over female reproductivity as they created a Hippocratic gynecology.» ${ }^{4}$. Afirmações semelhantes a esta são frequentes para explicar o incremento notável na publicação de obras sobre ginecologia a que se assistiu na Europa entre as últimas décadas do século XVI e o século $\mathrm{XVII}^{5}$. Este interesse masculino numa área tradicionalmente associada às mulheres tem sido entendido como consequência da divulgação dos tratados hipocráticos sobre estas

2 O Corpo Hipocrático é constituído por cerca de seis dezenas de tratados atribuídos a Hipócrates, mas de autores incertos e com temáticas diversas. Não representa, portanto, uma colectânea uniforme ou um qualquer sistema de teorização médica coerente. Sobre doenças das mulheres, o Corpo Hipocrático inclui De mulierum affectibus 1 e 2 (Mul.); De sterilibus (Ster.); De natura muliebri (Nat. Mul.); De uirginum morbis (Virg.). Têm interesse também nesta matéria os tratados: De semine (Genit.), De natura pueri (Nat. Puer.), De septimestri partu (Septim.), De octimestri partu (Oct.), De foetus exsectione (Foet. Exsect.) e o De superfetatione (Superf.).

3 Vejam-se, a título de exemplo, alguns excertos que, no livro 1 do De mulierum affectibus, descrevem

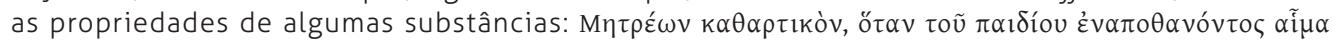

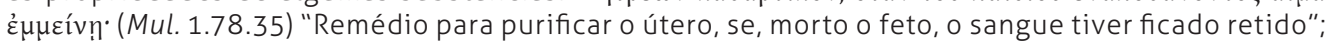

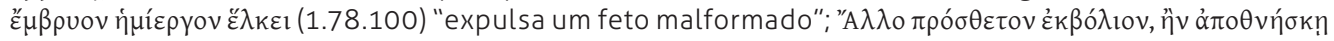

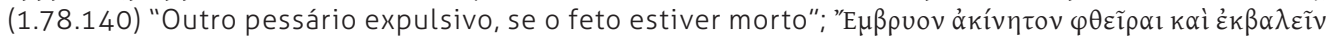

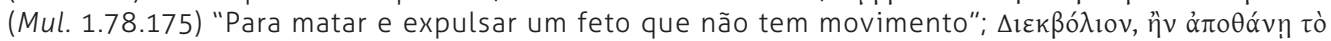

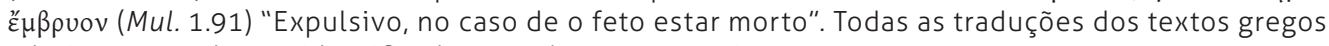
e latinos, quando não identificadas, são da nossa autoria.

4 Nancy Demand, "Monuments, midwives and gynaecology", in Ph. J. van der EIJK, H. F. HoRSTMANSHOFF, \& P. H. SCHRIJVERS (eds.), Ancient medicine in its socio-cultural context. Amsterdam, Rodopi, 1992, pp. 285-287.

5 Michael StolberG, "A woman down to her bones: the anatomy of sexual difference in the sixteenth and early seventeenth centuries", Isis 94 (2003), p. 288; Helen KING, Midwifery, obstetrics and the rise of gynaecology: the uses of a sixteenth-century compendium. Aldershot, Hants \& Burlington, Ashgate Publishing, 2007, p. 29. 
matérias, especialmente porque Galeno, à excepção de alguns tratados breves como o De uteri dissectione, não compusera um texto especificamente a elas dedicado ${ }^{6}$.

Assim, se, por um lado, se apresenta nestes textos um nível de conhecimento de índole popular, fundamentado principalmente na transmissão de receitas e associado ao desempenho das mulheres — parteiras e não só — , por outro lado, parece-nos evidente, na exuberância dos pormenores e numa certa tendência para mostrar capacidades técnicas alheias ao domínio feminino, a demonstração da proeminência do saber do médico que, especialmente numa situação desesperada como um parto difícil, se apresenta como superior e imprescindível. Recordemos que a presença do médico só se tornaria necessária precisamente quando o parto se desenrolava de forma anormal.

Os partos distócicos são tema recorrente nos tratados médicos da antiguidade relacionados com as doenças femininas e, na nossa opinião, parecem ter-se configurado como um tópico de cariz mais ou menos estável, que se repete quase sempre com as mesmas classificaçóes e características, mas que denota um interesse e uma sofisticação crescentes ${ }^{7}$. Nos tratados de ginecologia do século XVI, títulos de capítulos como «Difficultas partus» (Nicholas de la Roche, De morbis mulierum curandis liber, 1542), "De praeceptis et medicaminibus partus moram et difficultatem allevantibus» (Jakob Ruff, De conceptu et generatione hominis, 1554) ou "Quibus praesidiis partum acceleremus et foetum mortuum pellamus» (Luigi Bonacciuoli, Muliebrium liber, 1505) são indício seguro de que se mantinha o entendimento dos partos distócicos como uma área fundamental na medicina dedicada às doenças femininas.

É objectivo desta pesquisa a procura de traços comuns aos tratados médicos antigos e a duas obras de autores portugueses - as Curationum medicinalium centuriae de Amato Lusitano e o De universa mulierum medicina de Rodrigo de Castro Lusitano - no que concerne à definição e ao tratamento dos partos difíceis. Náo se trata de uma pesquisa exaustiva nem diacrónica, mas apenas de uma identificação preliminar de tópicos comuns. Tomamos, assim, como ponto de partida para este estudo um corpus constituído por textos gregos e romanos que se debruçam sobre partos distócicos, em especial os tratados hipocráticos De mulierum affectibus e De superfetatione $e^{8}$ e o tratado de ginecologia de Sorano de Éfeso, os Gynaikeia. Este autor de origem grega terá exercido medicina em Roma nos principados de Trajano e Adriano e teve uma importância notável, ainda que indirecta, na literatura acerca das doenças e condiçóes femininas, uma vez que o seu tratado foi cedo

6 Também por esta razão omitimos nesta pesquisa a obra galénica. O facto de circular sob o nome de Hipócrates um conjunto de tratados sobre condições femininas parece ter concedido uma certa autoridade aos autores que, especialmente por influência da tradução latina de CALVI, publicada em 1525. invocavam o pai da medicina para legitimar as suas obras. Veja-se, a este respeito, Helen KING, Hippocrates' woman: reading the female body in ancient Greece. London \& New York, Routledge, 1998, p. 13.

7 Veja-se, por exemplo, Ann E. HANSON, "A division of labor: roles for men in Greek and Roman births", Thamyris 1.2 (1994), pp. 157-202.

8 Os partos difíceis são também referidos em tratados médicos de carácter mais geral, como as Epidemias. 
abreviado e traduzido em língua latina ${ }^{9}$. Estas versóes simplificadas, em especial a Genecia, de um autor desconhecido, identificado nos manuscritos como Muscio ou Mustio (? c. 500), foram muito divulgadas na Europa. Apesar da problemática tradição manuscrita da obra de Sorano — chegou até nós um único manuscrito, e incompleto, dos Gynaikeia, encontrado já em pleno século xIx ${ }^{10}$ —, o livro IV dos seus Gynaikeia, dedicado às patologias ginecológicas a serem tratadas pelo recurso a substâncias medicinais ou a intervenções cirúrgicas, constitui uma fonte importante acerca da tradição médica dedicada aos partos distócicos. Autores de enciclopédias médicas como Aécio de Amida (séc. V-VI), ou Paulo de Egina (séc. VII), retomando a tradição, incluem também nas suas obras consideraçóes consistentes acerca deste assunto e por este motivo os incluímos também aqui.

Constituem uma segunda componente do corpus em análise as já referidas obras de Amato Lusitano e de Rodrigo de Castro Lusitano, ambas fundamentais na história da medicina em Portugal: as Curationum medicinalium centuriae, publicadas em 1556, e o De universa mulierum medicina de Rodrigo de Castro. No contexto do presente volume, Amato dispensa apresentaçóes. Dele analisamos um conjunto de casos reais em que o autor descreve a terapia a que recorreu quando chamado a ajudar mulheres em sofrimento devido ao que ele designa de partus diffciles. O De universa mulierum medicina é um tratado de ginecologia, publicado pela primeira vez em 1603 e em 1604, em dois tomos, em Hamburgo, onde o seu autor se instalara para fugir da Inquisição, e que foi reeditado durante décadas. Os dois volumes - um, De natura mulierum, especialmente teórico; o segundo, De morbis mulierum, de natureza prática — com quatro livros cada, tratam, de forma abrangente e documentada, condiçóes femininas como a concepção, a menstruação, a gravidez, o parto, o aborto, a infertilidade, etc., e constituem um reportório monumental acerca do estado da ciência do seu tempo, especialmente no diálogo que estabelece entre tradiçóes díspares, como a clássica e a escolástica, mas também e não menos importante, pela proeminência das novas ideias que por então enformam a medicina.

Abordamos hoje os elementos que nestas duas obras entroncam na tradição grega e romana acerca dos partos distócicos e como a reelaboração destes elementos no contexto da medicina dos séculos XVI e XVII permite distinguir e fundamentar o saber médico numa área maioritariamente reservada às mulheres.

A definição de parto distócico que é hoje em dia comummente aceite («parto difícil, causado por anomalias no feto ou na mãe» ${ }^{11}$ ) não anda muito longe das definições antigas, que associam

9 Sobre a pervivência da obra de Sorano na medicina ocidental, cf. Ann E. HANson \& Monica H. GREEN, "Soranus of Ephesus: Methodicorum princeps", ANRW II.37.2 (1994), pp. 968-1075, maxime pp. 1042 ss., e Yves Malinas, "Modernité de Soranos", in P. BurguiÈRe, D. GourevitCh \& Y. MALInAs, Soranos d'Éphèse. Maladies des femmes I. Paris, Les Belles Lettres, 2003², pp. LXVII-LXXIV.

10 Sobre a descoberta do Parisinus Graecus 2153 por Friedrich Dietz, cf. P. BuRGUIÈrE, "Histoire du Texte", in P. Burguière, D. Gourevitch \& Y. Malinas, Soranos d'Éphèse..., op. cit., 2003², pp. XLVII-LXV.

11 Veja-se, a título de exemplo: «Dystocia - difficult birth, caused by abnormalities in the fetus or the mother (...). Dystocia may arise due to uterine inertia, which is more common in a first labour; abnor- 
a difficultas pariendi a três, por vezes a quatro causas. Nos tratados hipocráticos, é de preferência

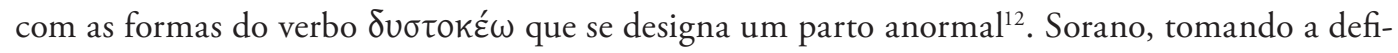
nição de Demétrio de Apameia, como o próprio Sorano seguidor de Herófilo de Alexandria e da escola metódica ${ }^{13}$, define distocia como um parto penoso ( $\left.\delta v \sigma \chi \varepsilon \rho \tilde{\eta}\right)$ ou difícil ( $\left.\mu \varepsilon \tau \grave{\alpha} \delta v \sigma \varepsilon \rho \gamma \varepsilon i ́ \alpha \varsigma\right)$ :

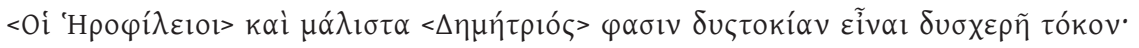

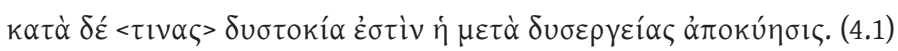

Os seguidores de Herófilo e especialmente Demétrio dizem que parto distócico é um parto penoso; para alguns, parto distócico é dar à luz entre dificuldades.

E prossegue com uma longa recensão das causas propostas para os partos distócicos por autores que o precederam (Díocles de Caristo, Cleofanto, Herófilo, Demétrio...), que vai citando e comentando. Na Genecia, Múscio reduz todas as consideraçóes de Sorano acerca das causas propostas pelos seus antecessores, abreviando-as e organizando-as de forma mais simplificada e acessível:

Quot sunt enim causae quibus laboriosus vel difficilis partus efficitur?

Plurimi duas causas esse dixerunt, unam apud eam quae parit, alteram apud ipsum infantem qui nasci habet. Alii vero iam tertiam causam addunt quae extrinsecus venire consuevit. Apud alios etiam quarta causa emergit, quae ex omnibus praedictis causis miscetur. (2.17.1)

Quantas são as causas de um parto penoso ou difícil?

A maioria dos autores disse que existem duas causas, uma relacionada com a parturiente, outra com a própria criança que nasce. Outros, porém, acrescentam uma terceira causa

mal fetal lie or presentation; absolute or relative cephalo-pelvic disproportion; (...)», Oxford Concise Medical Dictionary. Oxford University Press, $2010^{8}$, s. v. "Dystocia".

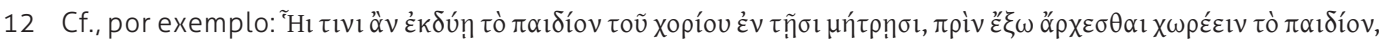

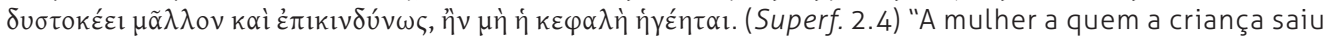
da placenta dentro do útero antes de começar a sair, tem um parto extremamente difícil e perigoso, se

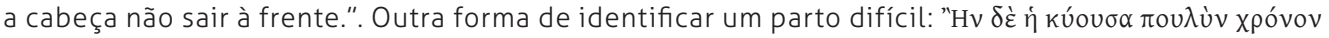

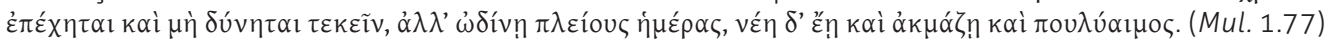
"Se uma mulher grávida depois de muito tempo não é capaz de dar à luz, mas tem dores durante muitos dias, é jovem e forte e tem muito sangue (...)".

13 Sobre a obra de DemÉtrio de Apameia, cf. H. von StADEn, Herophilus: the art of medicine in early Alexandria. Cambridge-New York, Cambridge University Press, 1989, pp. 506 ss. 
que costuma vir do exterior. Na obra de outros surge ainda uma quarta causa, que é composta por todas as causas referidas antes.

Aécio de Amida (Iatricorum liber 16.22) divide em três tipos os factores que podem difi-

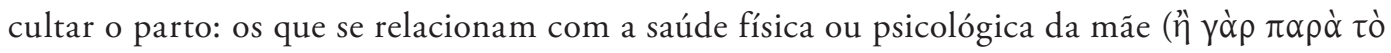

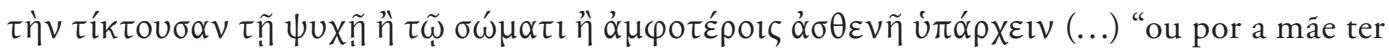

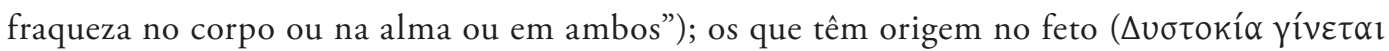

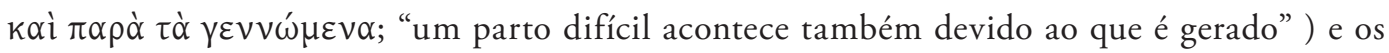

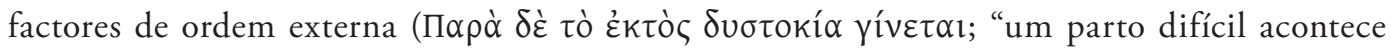
devido ao exterior"). Paulo de Egina (Epitomae Medicae 3.76) apresenta quatro causas:

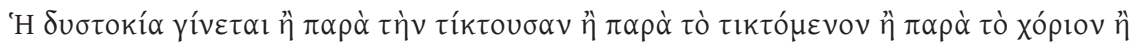
$\pi \alpha \rho \dot{\alpha} \tau \dot{\alpha} \check{\varepsilon} \xi \omega \theta \varepsilon v^{.}$

Um parto distócico acontece ou devido à parturiente, ou devido ao feto, ou devido à placenta, ou devido a causas externas. ${ }^{14}$

Nos textos em análise, distinguem-se efectivamente e de um modo geral as causas relacionadas com a saúde materna, as que são causadas pelo estado do feto e as condiçóes externas que podem condicionar o decorrer normal do parto, como condiçóes climatéricas adversas ou mesmo a inexperiência da parteira ou do médico que orienta o parto.

Amato recorre principalmente ao vocabulário associado à diffcultas ou ao labor para designar um parto demasiado longo e penoso ${ }^{15}$. Rodrigo de Castro, pelo contrário, tem uma abordagem sistemática e fundamentada na distinção entre um parto natural, assunto que explora no primeiro capítulo desta secção, e os seus opostos, que trata nos capítulos subsequentes. Esta oposição é apresentada logo no início quando justifica a inclusão de um capítulo sobre partos normais no volume da obra que dedica às condiçôes patológicas. Para que um parto seja designado como um parto normal deve obedecer, segundo Castro, a cinco condiçóes:

14 Nas Definitiones Medicae 19.456, uma obra atribuída a GALENo, mas de autoria duvidosa, afirma-se

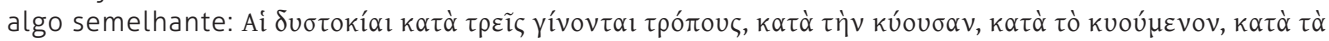
$\xi \xi \xi \omega \varepsilon \varepsilon v$. "Os partos distócicos acontecem de três maneiras: devido à grávida, devido ao feto, devido a causas externas.".

15 Apenas alguns exemplos: (...) difficulter pariebat (Cent. VI, curas 51 e 86) refere-se em ambos os casos ao parto de fetos mortos; ut plerunque partum difficilem habentibus evenit (Cent. I, cura 93) cum per triduum in emittendo foetu, graviter laboraret (Cent. V, cura 34) designam o parto de gémeos. 
(...) ad naturalem partum quinque requiri conditiones. Prima est, ut fiat profecto iam foetu; Secunda ut debito tempore; Tertia ut debita figura; Quarta ut levibus symptomatibus; Quinta ut evacuationibus debitis. (2.4. cap. 1, pp. 445-446)

(...) para um parto natural são necessárias cinco condições: a primeira, que aconteça quando o feto está formado; a segunda, que aconteça no tempo oportuno; a terceira na posição conveniente, a quarta com sintomas toleráveis; a quinta com evacuaçóes convenientes.

Qualquer parto em que não se verifique uma destas situaçóes é um parto que não é natural: o nascimento de um feto morto ou um aborto (não se cumprem a primeira e a segunda), o parto de um feto em posição anormal (não se cumpre a terceira), um parto difícil e penoso (não se cumpre a quarta), e, por fim, um parto seguido de retenção da placenta (não se cumpre a quinta). Uma distinção fundamental no De universa mulierum medicina, que não está presente em nenhuma das obras em análise, é a que o autor estabelece entre partus vitiosus e partus difficilis et laboriosus: o primeiro é o nascimento de um feto em posição anormal, o segundo um parto com sofrimento prolongado e que representa um risco para a mãe:

Dicitur autem difficilis partus ille, qui cum foetus vel matris periculo accidit, vel quia cum gravissimis fit symptomatibus, vel quia tardius procedit, ita ut longo tempore prematur mulier. (2.4. cap. 6, p. 478)

Diz-se um parto difícil aquele que acontece envolvendo perigo para o feto ou para a máe, quer porque se desenrola com sintomas muito graves, quer porque avança de forma muito lenta, de modo a que a mulher seja atormentada por muito tempo.

Entre as causas relacionadas com a saúde materna, os autores são mais ou menos unânimes ao referir que não só a condição física da parturiente, mas também o seu estado psicológico podem originar dificuldades no parto. Sorano, reproduzindo o pensamento do já citado Demétrio, realça efectivamente a importância do equilíbrio mental e emocional da paciente:

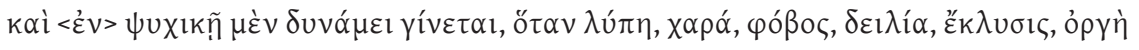

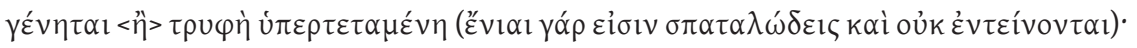

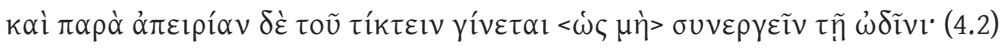

O parto difícil deve-se também à força psíquica quando acontece a dor, a alegria, o medo, a timidez, a fraqueza, a ira, ou uma vida de luxo exagerado (pois algumas mulheres são 
indulgentes e não fazem esforços). Acontece também por falta de experiência em dar à luz: [a parturiente] não colabora no trabalho de parto.

O bem-estar psicológico da mãe é factor essencial no momento em que se prepara o parto ${ }^{16}$, mas é absolutamente determinante se este se complicar. Entre as causas de distocia relacionadas com a parturiente, Sorano adverte a parteira para que tenha sempre cuidado de modo a que os seus gestos, o seu olhar, as suas palavras não assustem a parturiente, com frequência demasiado jovem para entender o que se passa à sua volta. Esta falta de experiência é, aliás, enumerada entre os factores que podem condicionar o desenrolar do parto, por poder originar a retracçáo do corpo da mãe, que deixa de colaborar com a parteira. A primípara é, normalmente, uma paciente a ter sob vigilância ${ }^{17}$. Veja-se, por exemplo a afirmação do tratado De mulierum affectibus:

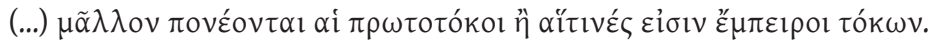

(...) Sofrem mais as primíparas do que as que têm experiência no parto.” (Mul. 1.72)

Sorano refere também a falta de experiência das primíparas como um obstáculo a um parto

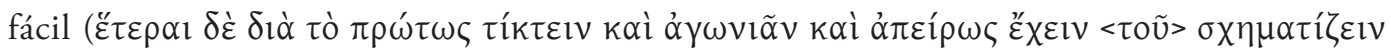

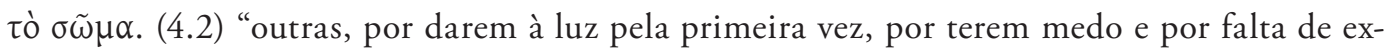
periência em colocar o corpo na posiçáo certa"), mas assinala igualmente as jovens que casam demasiado cedo, cujo corpo não está ainda preparado para o parto:

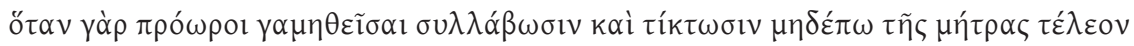

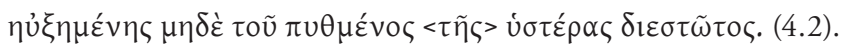

Pois, casadas antes do tempo adequado, engravidam e dáo à luz quando o útero ainda não atingiu o seu crescimento máximo nem o fundo da matriz se abriu.

Entre os factores de ordem física, assumem relevo, além das patologias do útero ou do colo do útero, que dificultam ou impossibilitam a passagem do feto, a extrema magreza ou, em

16 Rodrigo de Castro, por exemplo, aconselha as parteiras que dêem ânimo à parturiente consolando-a com a esperança de um parto de um rapaz: Parientem obstetrix (...) etiam verbis consoletur cum bona spe felicis ac masculi partus, eo enim mulieres sese gaudent (...). "Que a parteira (...) anime a parturiente com a esperança de um parto fecundo e de um rapaz, porque as mulheres alegram-se com isso." (II. 4. cap. 1, p. 448).

17 Cf. também a observação de Rodrigo de Castro: parturiens puella (...) ob imperitiam corpus apte praeparare ignorat. "A jovem parturiente (...) por falta de experiência não sabe como preparar convenientemente o corpo." (II. 4. cap. 6, p. 472). 
oposição, a obesidade da mãe. Os problemas relacionados com o peso são aliás frequentemente assinalados como obstáculo a todo o ciclo de procriação, já que tanto as mulheres obesas como as magras em demasia têm, de acordo com os tratados médicos antigos, dificuldade em engravidar, ou, se engravidam, são incapazes de levar a gravidez a termo ${ }^{18}$. Sorano refere igualmente a obesidade da mãe entre as causas relacionadas com a condição física da parturiente ${ }^{19}$.

É também notado por estes autores que o facto de a mulher grávida ter uma vida sedentária e inactiva dificulta o parto, enquanto o exercício é benéfico, não apenas porque favorece um parto normal, mas também porque contribui para a saúde da criança.

Entre as causas relacionadas com o feto, todos os autores referem o seu tamanho, na totalidade ou numa parte do corpo, um feto morto, o nascimento de gémeos ou a posição anormal no útero materno. Veja-se o que diz Sorano:

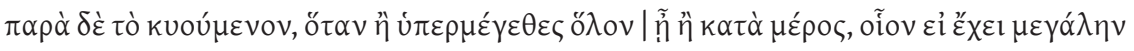

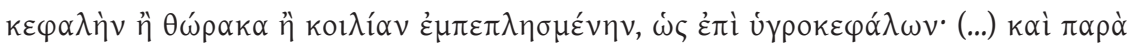

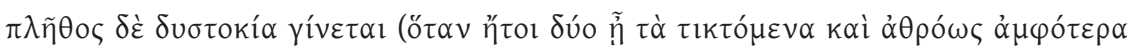

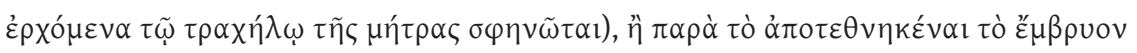

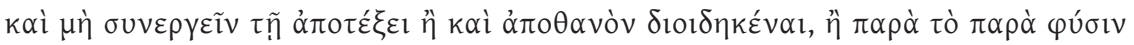
$\dot{\varepsilon} \sigma \times \eta \mu \alpha \tau i ́ \sigma \theta \alpha$ l. (4.2)

Causas relacionadas com o feto: quando é demasiado grande quer no corpo inteiro quer numa das partes, como quando tem a cabeça ou o tórax grandes ou o ventre inchado, como acontece nos hidrocéfalos. (...) Ocorre também um parto distócico devido ao número (quando são dois e ambos se aproximam em conjunto do colo do útero causando uma obstrução), ou por o feto estar morto e não colaborar no parto ou por, visto estar morto, estar intumescido, ou por se apresentar numa posição anormal. ${ }^{20}$

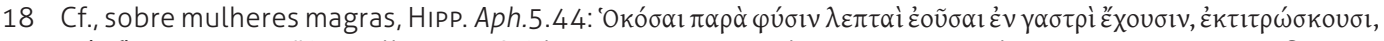
$\pi p i v$ ทे $\pi \alpha \chi v v \theta \tilde{n} v \alpha$. "As mulheres grávidas que são anormalmente magras abortam enquanto não ficarem mais fortes.". Ideias semelhantes em HIPP. Ster. 237 e Nat. Mul. 19. Sobre mulheres obesas, cf. Aph.

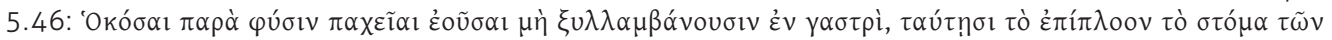

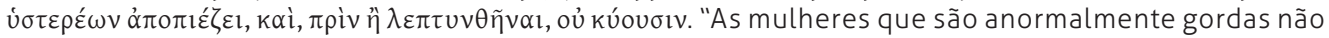
concebem no seu ventre, pois a estas a gordura pressiona-lhes a entrada do útero e, enquanto não emagrecerem, não engravidam.". Em HıPp. Ster. 229 e Nat. Mul. 20 fazem-se afirmações idênticas.

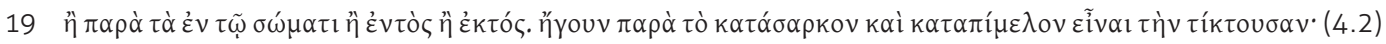
"Há ainda causas físicas, internas ou externas, como a parturiente ser extremamente corpulenta e gorda.". Esta ideia é repetida verbatim por AÉcıo de AMIDA (lat. 16.22).

20 As causas relacionadas com o feto não são muito diferentes nos outros autores: "Hv $\delta \dot{\varepsilon} \gamma u v \alpha \iota k i ̀ ~ \varepsilon ́ v ~ \gamma \alpha \sigma \tau \rho i$

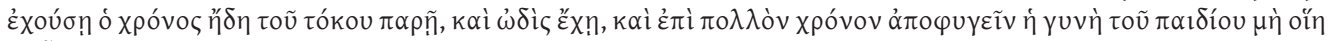

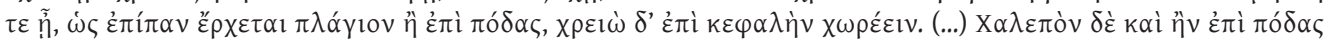

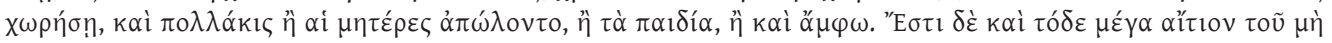


Rodrigo de Castro, repetindo uma ideia que remonta aos tratados hipocráticos, afirma que dificulta o parto um feto maior do que o normal ou, pelo contrário, demasiado pequeno, porque este náo consegue romper as membranas e àquele o útero não consegue adaptar-se. A criança é deste modo vista como incapaz de desencadear o parto e de fazer o seu próprio caminho em direcção à vida:

Ex parte foetus causae sunt, si inusitatae magnitudinis existat, aut exiguus nimis, qui nec vincula disrumpere queat: nec uterus ei adaequetur. Aut si magni capitis, vel admodum exigui, hic enim non aperit vias, nec ab obstetrice apprehendi potest; ille difficulter egressum invenit. Similiter si parvi ponderis aut debilis sit, quia tunc seipsum adminiculantem non praestat. (2.4. cap. 6, p. 472)

Da parte do feto as causas são: se tem um tamanho grande inusitado ou demasiado pequeno que nem consegue romper os vínculos nem o útero a ele se adequa. Ou se tem a cabeça grande ou muito pequena, pois este não abre o caminho nem pode ser puxado pela parteira; aquele dificilmente encontra a saída. Do mesmo modo, se tiver pouco peso ou se for débil, porque não é capaz de se auxiliar a si próprio.

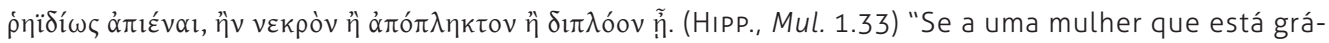
vida passou já o momento do parto e sente dor, e depois de ter passado muito tempo a mulher não foi capaz de expulsar a criança, em geral está em posição lateral ou podálica, sendo necessário que saia de cabeça. (...) É também causa de dificuldades se sair de pés, e muitas vezes morrem as mães ou as crianças ou ambos. Existe outra razão importante que o impede de sair facilmente: quando

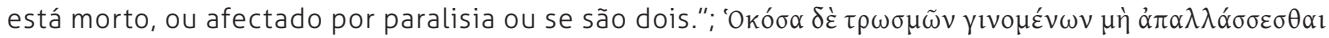

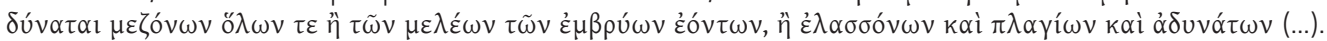
(Mul. 1.68) "No caso de, tendo ocorrido um aborto, não se poder expulsar o feto por ser demasiado grande no todo ou num dos membros, ou por ser pequeno, estar de lado e fraco (...)"; Quomodo dicunt per infantem qui nasci habet difficilimum partum dari? Scilicet qui naturaliter grande caput habeat vel omne corpus, vel tres manus, aut certe hydropicus sit vel gibberosus vel languidus aut inflatus vel mortuus aut positione contra naturam. (Múscio, Genecia 17.3) "Como dizem que o parto se torna muito difícil devido à criança que vai nascer? Seguramente aquele que tem por natureza a cabeça grande ou todo o corpo, ou três mãos, ou se é hidrópico, corcovado, fraco, ou se estiver intumescido ou morto ou em

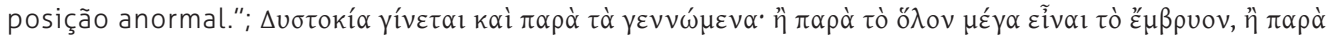

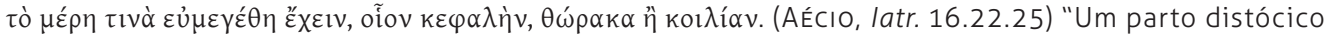
acontece também devido ao que é gerado: ou por o feto ser todo ele grande, ou por ter alguma parte

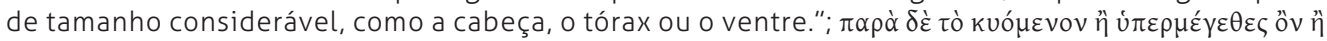

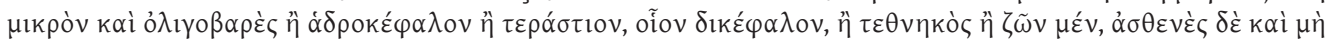

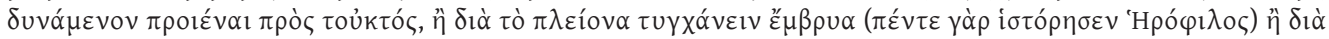

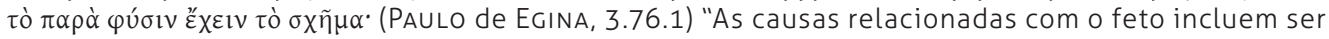
demasiado grande ou pequeno e leve, hidrocéfalo ou monstruoso, como ter duas cabeças, ou estar morto ou ter ainda vida mas ser fraco e incapaz de avançar para o exterior, ou acontecer serem muitos fetos (Herófilo registou cinco) ou estar uma posição anormal.". 
A gestação de um feto monstruoso é igualmente uma das causas apontadas para um parto difícil ${ }^{21}$. Diga-se que este tema gerará grande interesse na literatura do período renascentista, com a publicação de vários tratados, alguns com representaçóes de seres deformados e entendidos como nascimentos prodigiosos ou como uma punição divina ${ }^{22}$. Amato, por exemplo, descreve um monstro nascido no terceiro ou quarto mês de gestação de uma mãe habitante de Ancona. Não é certo se ele próprio o terá visto, mas descreve-o com pormenor:

\begin{abstract}
Mulier Anconitana monstrum quoddam peperit: nam tertio vel quarto mense impregnationis informe quoddam carneum corpusculum emisit, quod omnino hirsutum erat et pilosum, quatuor habens óculos, duas nares, quatuor aures, labra vero deformia, ut omnibus esse admirationi. (Cent. III, cura 57)

Uma mulher anconitana deu à luz um monstro. No terceiro ou quarto mês da gravidação deitou fora um corpúsculo carnoso, informe, totalmente hirsuto e cabeludo, com quatro olhos, dois narizes, quatro orelhas e lábios disformes. A todos causava espanto. ${ }^{23}$
\end{abstract}

Diz ainda que enquanto escreve (cum haec scribo), chegou a Ancona um rapaz da Ilíria, com seis anos, aparentemente normal, mas trazendo consigo (ou em si?) um monstro que lhe ocupava o espaço entre o umbigo e o tórax e tinha a forma de outro corpo de criança, sem cabeça, mas com braços e pernas, ainda que imóveis ${ }^{24}$.

A morte do feto in utero deve ter sido muito frequente. Expressóes com o significado de "para expulsar um feto morto" são repetidas à exaustão para introduzir uma panóplia de receitas e terapêuticas que aparecem desde os textos hipocráticos a Plínio-o-Velho ${ }^{25}$ e se mantêm na tradição. Nas curas 51 e 86 da Centúria VI, Amato descreve precisamente dois casos em que fetos mortos no ventre materno originaram partos prolongados e dolorosos. Recordemos apenas a situação

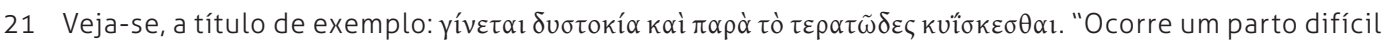

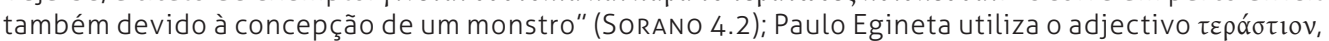
que significa "monstruoso" ou "prodigioso". Rodrigo de Castro refere-se a um foetus monstruosus como causa de dificuldades no parto.

22 Veja-se Lorraine DASTON \& Katherine PARK, Wonders and the order of nature, 1150-1750. New York, Cambridge, Mass., Zone Books, 1998.

23 Amato Lusitano, Centúrias de curas medicinais, vol. II (trad. Firmino CRespo). Lisboa, Universidade Nova de Lisboa, s. d., p. 267.

24 Amato Lusitano, Centúrias..., op. cit., p. 268. Para dar veracidade ao seu relato Amato termina o texto com a data: Fuit autem hoc monstrum Anconae, anno 1552. "Este monstro esteve em Ancona no ano de 1552.".

25 Cf. supranota 2. De Plínı, vejam-se, por exemplo, Nat. 23.62; 24.22; 24.102; 26.152; 26.153; 26.154; $26.157 ; 26.158 ; 26.161 ; 27.30 ; 28.252$. 
desesperada de Aloísia, a quem só depois de três dias de sofrimentos atrozes e quando já todos a davam como morta, conseguiram extrair, em pedaços, o filho sem vida. Rodrigo de Castro, repetindo o que se escreve no De superfetatione, diz que um feto morto se identifica se a máe se deitar de lado. Se o feto já não tiver vida, mover-se-á como uma pedra ${ }^{26}$. A este assunto dedica todo um capítulo nesta secção da sua obra, que faz seguir por outro acerca da prática da cesariana, uma novidade do seu tempo, divulgada por François Rousset, na sua obra Traité nouveau de l'hysterotomotokie ou enfantement Caesarien, publicada em Paris em 1581 e posteriormente traduzida para língua latina e incluída nos Gynaeciorum libri, um compêndio monumental de obras dedicadas a doenças e condiçóes femininas, muito divulgado na Europa.

Também os partos múltiplos são enumerados entre os partos difíceis. Herófilo, citado por Sorano e Paulo de Egina, teria descrito o caso de uma mulher que, em cada um de três partos, tinha tido cinco filhos, ou seja, um total de quinze crianças ${ }^{27}$.

De Amato citamos a cura 34 da Centúria V, a das meninas amarelas, as puellae luteae, irmãs gémeas que nasceram amarelas devido ao açafrão que era um dos ingredientes da medicação aconselhada por Amato, depois de um parto que se prolongou também por dias. Os partos

26 Cognosces foetum in utero mortuum esse, si admota manu amplius moveri non percipitur, sed decumbente foemina in latus, in id devolvitutr etiam infans, veluti immobile quoddam saxum. "Saber-se-á que o feto está morto no útero se colocando a mão [i. e. no ventre] se perceber que já não se move, mas, deitando-se a mulher de lado, para esse lado vira-se também a criança, imóvel como uma qualquer pedra.". Veja-se

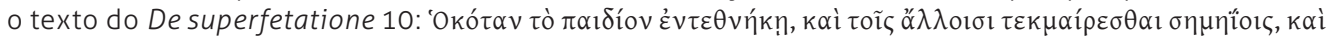

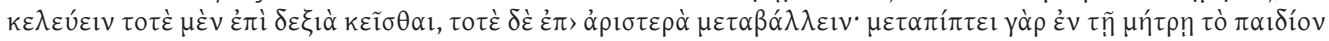

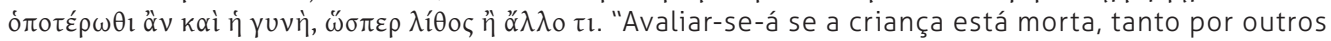
sinais como pedindo [à mãe] que se deite primeiro sobre o lado direito, depois que mude para o lado esquerdo, pois a criança no útero vai para a direcção para a qual se virou a mãe, como uma pedra ou algo assim.".

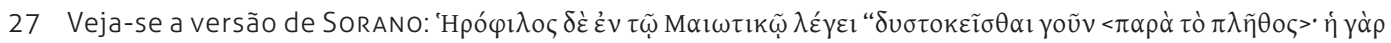

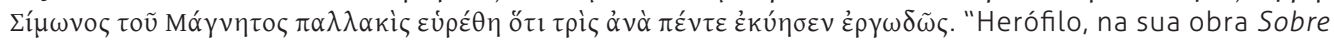
os Partos afirma: "acontecem partos difíceis devido ao número [de fetos]: deu-se o caso da concubina de Símon da Magnésia que em três vezes deu à luz cinco filhos entre dificuldades.". Cf. o texto de PAULo de EGINA, supra n. 17. Veja-se também o texto de Aristóteles: "Na maior parte dos casos e na generalidade dos países, as mulheres dão à luz uma só criança; mas é também frequente e ocorre por toda a parte que tenham duas, como é o caso do Egipto. Podem até ter três ou quatro gémeos, em certas regiões bem definidas (...). O máximo é cinco, situação que já se verificou várias vezes. Houve um único caso de uma mulher que, em quatro partos, deu à luz vinte filhos; teve, de facto, cinco gémeos de cada vez, e conseguiu criar a maior parte." ARISTóteles, História dos Animais II (tradução de M. F. Sousa e SILVA). Lisboa, Imprensa Nacional-Casa da Moeda, 2008, p. 215. De acordo com Aulo Gélio, o imperador Augusto terá mandado erigir uma estátua a uma sua escrava que deu à luz quíntuplos: Sed et diuo Augusto imperante, qui temporum eius historiam scripserunt, ancillam Caesaris Augusti in agro Laurente peperisse quinque pueros dicunt eosque pauculos dies uixisse; matrem quoque eorum non multo, postquam peperit, mortuam, monumentumque ei factum iussu Augusti in uia Laurentina, inque eo scriptum esse numerum puerperii eius. (Gel. 10.2.2). "Mas também no reinado do divino Augusto, dizem aqueles que escreveram a história do seu tempo, uma escrava de César Augusto deu à luz no campo de Laurento cinco rapazes e que eles viveram poucos dias; a mãe deles morreu também não muito depois do parto. Por ordem de Augusto, foi construído em memória dela um monumento na via Laurentina, e nele estava escrito o número dos filhos dela.". 
de gémeos suscitaram sempre alguma surpresa, ora acolhidos como sinal de fecundidade e prosperidade, ora interpretados como símbolo de crise e de carestia ${ }^{28}$.

A causa de distocia mais comentada é, todavia, a apresentação anormal do feto no ventre

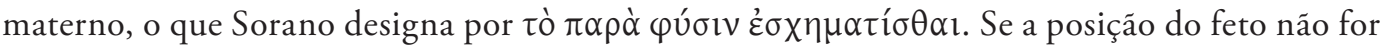
a cefálica, unanimemente apresentada nestes textos como a posição natural e conveniente ao parto, ou a podálica, deve tentar-se corrigi-la, manipulando interna e externamente o corpo da criança ${ }^{29}$. No livro 1 do De mulierum affectibus explicam-se as dificuldades geradas por um feto em posição anormal recorrendo a uma imagem muito sugestiva: como acontece com um caroço de azeitona dentro de um lekytos, de um vaso de gargalo alto e estreito, que não se consegue tirar se náo estiver alinhado com a abertura, o mesmo sucede com uma criança numa posição que não a cefálica ou a podálica ${ }^{30}$.

As apresentações que um feto podia assumir dentro do útero seriam tema de uma série de gravuras que acompanhariam o texto de Sorano. Lamentavelmente, o único manuscrito que o conserva, o Parisinus Graecus, apresenta os espaços correspondentes em branco. Os manuscritos da Genecia de Múscio, bem mais numerosos, apresentam estas ilustraçóes, que foram divulgadas na Europa desde muito cedo. De facto, circularam mesmo separadamente do texto e chegaram, por vezes, a ser incluídas como anexo em textos de autores posteriores ${ }^{31}$. Podemos observar estas imagens num manuscrito do século IX, que mostra as posiçóes secundum naturam e depois as praeter naturam ${ }^{32}$.

Amato Lusitano aconselha o seu leitor, especialmente se for Hispanicus e considerar sacrilégio cortar um cadáver, a procurar informações sobre as apresentações do feto in utero nos modernos livros de anatomia. Esta referência, entendida como uma alusão a Vessálio, pode, no entanto, remeter o leitor para as muitas versóes das imagens da Genecia de Múscio que circulavam por então também na obra de autores contemporâneos como Eucharius Rösslin, uma vez que na obra de Vessálio não se representa o feto dentro do útero materno ${ }^{33}$. Rodrigo de Castro referese precisamente a estas imagens ao descrever as posiçóes da criança:

28 Sobre os nascimentos múltiplos, veja-se V. DASEN, "Multiple Births in Graeco-Roman Antiquity", Oxford Journal of Archaeology 16.1 (1997), pp. 49-63.

29 Para algumas descrições destas manobras, cf., por exemplo, Sorano 4.4; Múscio, Genecia 2.18.11.

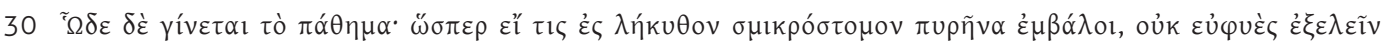

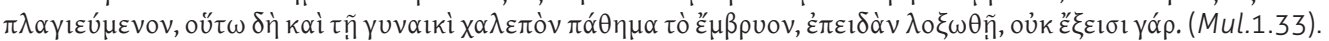
"O sofrimento acontece pelo seguinte: como se alguém tivesse colocado dentro de um vaso de entrada pequena um caroço de azeitona, que não tem uma forma adequada para ser retirado de lado, assim também o feto, se estiver de lado, é causa de grande sofrimento para a mulher, pois não sai.".

31 Cf. Hanson \& Green, "Soranus...", op. cit., pp. 1023-1024, e Monica H. Green, "The sources of Eucharius Rösslin's Rosegarden for Pregnant Women and Midwives (1513)", Medical History 53 (2009), pp. 167-192.

32 As imagens podem ser visualizadas em http://wellcomeimages.org/indexplus/image/M0007236.html.

33 Afirma Amato: Caeterum, quomodo gemini in utero ex adversa figura sedeant, et quo modo singulus singulis involucris et membranis circumvolvatur, ad anatomicos libros hodiernos, miris depictos figuris, 
(...) quas omnes figuras Hippocrates posuit, eas vero, ac plures ad easdem reducendas depinxit Eucharius Rodion. (2.4. cap. 5, p. 468)

(...) todas estas apresentaçôes foram expostas por Hipócrates, mas a estas e a muitas que podem ser resumidas a estas representou-as Eucharius Rösslin.

A descrição das manobras necessárias para colocar o feto na posição indicada para nascer é longa nestes textos ${ }^{34}$, mas acompanhada normalmente pela afirmação de que, se não se consegue extrair a criança de modo nenhum, deve recorrer-se a uma cirurgia, já descrita nos tratados hipocráticos e que consistia em desmembrar o feto morto, retirando-o posteriormente por partes ${ }^{35}$. Também Celso, que terá vivido na primeira metade do século I d. C., autor do De medicina, parte integrante da sua obra enciclopédica que abrangeria outros assuntos, descreve com pormenor esta cirurgia, desde as partes do corpo do feto que se devem ir amputando e extraindo até aos instrumentos mais indicados para o fazer (7.29). Trata-se, todavia, e todos os autores o afirmam, de uma cirurgia de riscos elevados para a mãe, cuja vida se pretende salvar, e que não deve ser realizada antes de a informar dos perigos que corre (4.9). No De superf. 7 , recomenda-se que se cubra a cabeça da parturiente, de modo a que esta não se atemorize. $\mathrm{Na}$ cura 51 da Centúria VI, depois de dois dias de sofrimentos intoleráveis, da aplicação, aconselhada por Amato perante a desistência das parteiras, de fomentaçóes e de substâncias esternutatórias, saiu do útero da jovem Aloísia o braço enegrecido do seu filho morto. Depois de partido o braço, um dexter chirurgus introduziu as mãos no ventre da mãe e extraiu a criança. Diz Amato que se isto não tivesse sido eficaz, teria de recorrer-se a um instrumento conhecido pela designação de "espéculo da matriz" para retirar o feto, inteiro ou por pedaços ${ }^{36}$.

recurrite, si modo vobis praesertim Hispanis, quibus piaculum est cadaver considere, non contingat aliter experire. (Cent. VI, cura 51) "Como é que os gémeos estão colocados no útero, em posição adversa, e como estão envolvidos cada um com as suas membranas ou invólucros recorra-se aos modernos livros de anatomia, com gravuras de admirável desenho, se, no entanto (especialmente aos hispânicos, para quem é crime retalhar um cadáver) não calhar experimentar de outro modo." AMATo LusitANo, Centúrias..., vol. IV, op. cit., p. 84.

34 SORANO 4.4.

35 SORANO 4.9-13; MúsCIO 2.18.26ss.; AÉCIO 16.23. A embriotomia é já descrita nos tratados hipocráticos, por exemplo em Mul. 1.68-70; Foet. Exsect. 1 e Superf. 7, o que atesta a antiguidade da sua prática.

36 Rodrigo de CASTRO, sobre a possibilidade de desmembrar um feto vivo no ventre materno afirma: ac etiamsi nulla medicamenta prosint, puer tamen vivus dissecari nulla ratione debet, quamvis Avicenna, Aëtius, \& Moschio id praecipiant, non enim licet unum interficere, alterius vitae gratia, sed implorato divino auxilio medicamentis, insistendum. (2.4. cap. 6, p. 477) "E ainda que nenhum medicamento seja eficaz, todavia por nenhuma razão se deve dilacerar uma criança viva, mesmo que Avicena, Aécio e Múscio o aconselhem. É que não é lícito matar uma pessoa por causa da vida de outra, mas, depois de implorar a ajuda divina, deve-se continuar com o uso de medicamentos.". 
Não cabe no âmbito desta pesquisa uma análise das substâncias cujo uso se recomenda para acelerar o parto. Não podemos, porém, deixar de referir a utilização de substâncias que provocam o espirro, como o heléboro e a pimenta, especialmente porque a utilização destas substâncias está relacionada com o muito citado Aforismo 5.35 de Hipócrates:

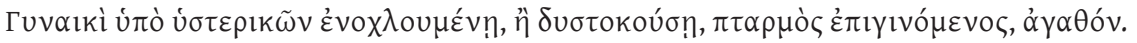

A uma mulher afectada por patologias uterinas ou num parto difícil, se lhe sobrevier um espirro, é bom. ${ }^{37}$.

O espirro era uma forma de sacudir o corpo da paciente que poderia levar a uma mais fácil expulsão do feto. No De mulierum affectibus afirma-se:

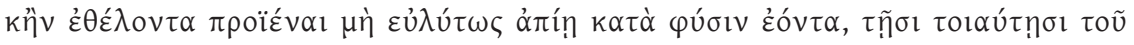

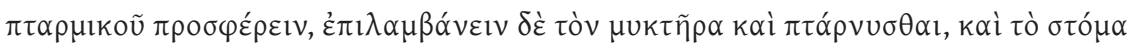

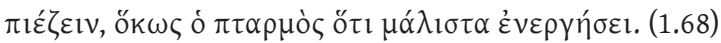

e se [o feto] querendo avançar e estando em posição normal, não sai facilmente, nestas circunstâncias aplicar algo que provoque o espirro, fechar o nariz e espirrar e fechar a boca para que o espirro seja o mais forte possível.

Amato é defensor desta prática, louvando - mas nunca o bastante, segundo o próprio Hipócrates, senex ille, naturae verus minister, e citando o aforismo 5.35. Afirma ter ele próprio visto muitas vezes um espirro acelerar um parto difícil ${ }^{38}$.

37 Veja-se a tradução de CeLSO: Quae locis laborat aut difficulter partum edit, sternumento leuatur. ("Aquela que sofre devido aos órgãos genitais ou que dá à luz num parto difícil é aliviada por um espirro."). Sobre as referências hipocráticas ao espirro como forma de facilitar o parto, cf. Ann Elis Hanson, "Continuity and change: Three Case Studies in Hippocratic Gynaecological Therapy and Theory", in Sarah Pomeroy (ed.), Women's History and Ancient History. Chapel Hill, University of North Carolina Press, 1991, pp. 91ss..

38 Porro interim haec agebamus, sternutationem ciebamus condiso, hoc est, struthio, sive lanaria dicta herba, helleboro, pipere, euphorbio, et similibus, prout, nos docuit agendum, nunquam satis laudatus senex ille, naturae verus minister, libro quinto suorum aphorismorum, aphor. 35. dicens mulieri, quae uterinis molestatur, aut difficulter parit, superveniens sternutatio, bonum. Vidimus autem nos difficulter parientes, a repetita sternutatione, brevi parere, quia vehementiore concussu, atque fervore, partim quidem naturam excitat, partim vero excernit, quae partibus corporis firmiter infixa adhaerent. (Cent. V, cura 34) "Entretanto, enquanto trabalhávamos nisto, provocávamos o espirro com struthion, isto é, saponária, a chamada erva-dos-pisoeiros (lanária), heléboro, pimenta, eufórbio e semelhantes, conforme nos ensinou a fazer aquele nunca assaz louvado Ancião, verdadeiro ministro da natureza, no livro $5^{\circ}$ dos seus Aforismos, aforismo $35^{\circ}$, ao dizer: "À mulher que é molestada por estrangulações uterinas ou tem parto difícil, é bom sinal o sobrevir-lhe espirro". Nós temos visto parturientes difíceis darem à luz 
Se isto não for eficaz, torna-se necessária uma intervenção mais violenta que consistia também em sacudir o corpo da paciente, mas de forma bem mais vigorosa. É o que se afirma no mesmo tratado hipocrático, logo de seguida: a paciente deve deitar-se numa cama sólida a que será atada, cama que será sacudida por dois homens. Em De exsect. 4, a parturiente deve ser colocada por cima de um lençol e, agarrada pelos pés e pelos braços por mulheres, deve ser sacudida pelo menos dez vezes. Depois será sacudida alternadamente pelos braços e pelas pernas. Aqui as manobras têm como finalidade fazer com que o feto numa posição anormal tenha espaço no útero para se reposicionar de forma adequada ${ }^{39}$.

Nos casos descritos nas Centúrias, por exemplo, estas duas formas de terapia são constantes. O recurso a substâncias esternutatórias constitui, a par da sucussão, o método mais utilizado por Amato para acelerar um parto difícil. Na cura 21 da Centúria VI, que se refere a uma mulher primípara em sofrimento, ordenou que se agarrasse a parturiente a uma corda suspensa do tecto e que fosse sacudida por um homem robusto. Receitou igualmente substâncias para provocar o espirro, o que acabou por permitir que expulsasse a criança no espaço de um dia.

Amato parece até, por vezes, acreditar que estes métodos causam uma certa impressão nas pessoas que assistem, incluindo nas parteiras. Veja-se por exemplo o parto antes citado das chamadas meninas amarelas:

Pinta uxor Pharasii, musici insignis, cum per triduum in emittendo foetu, graviter laboraret, ad eam iuvandam accersiti sumus. Ac post multa ob obstetricibus adhibita, et machinata, hoc illi ebibendum dedimus medicamentum. (...) Hoc enim epoto et repetito medicamento, duas peperit puellas, omnino luteas, ob quem colorem assistentes mulieres admirabantur. Caeterum, nos colorem hunc, a croco ebibito contractum esse docuimus. (Cent. V, cura 34)

A esposa do insigne músico Pharasi, de nome Pinta, há já três dias que procurava dar à luz uma criança com sofrimento e, para lhe darmos o nosso auxílio, chamaram-nos. Depois de muitos tratamentos feitos e engendrados pelas parteiras, demos-lhe a beber o seguinte remédio (...). Tendo tomado e repetido este medicamento, deu à luz duas meninas completamente amarelas. A cor causou grande admiração às mulheres assistentes. Por isso esclarecemos que esta cor tinha sido causada pelo croco bebido. ${ }^{40}$

rapidamente após repetidos espirros, visto que, pela sacudidela ou agitação mais veemente, por um lado se excita a natureza, por outro se desagrega aquilo que aderia com firmeza a partes do corpo." Amato Lusitano, Centúrias..., vol. III, op. cit., p. 224.

39 A mesma intervenção no texto de Rodrigo de CASTRo (2.4. cap. 5, p. 472).

40 amato Lusitano, Centúrias..., vol. III, op. cit., p. 225. 
Note-se que a relação entre o médico e as parteiras que podemos reconstituir a partir destes textos denota, com frequência, uma certa desconfiança dos médicos em relação a estas. Admonições como "cuida para que as parteiras não dilacerem o útero", ou "que as parteiras não recorram a práticas supersticiosas" são muito frequentes ${ }^{41}$. Também Amato mostra uma certa desconfiança em relação às práticas destas, que considera prejudiciais ${ }^{42}$. Rodrigo de Castro afirma que uma das medidas que a grávida deve tomar antes do parto é precisamente a escolha de uma boa parteira, arte que, segundo afirma, não é conveniente para os homens:

Igitur ante partum eligenda obstetrix prudens, muliebrium affectionum docta, \& obstetricandi exercitatione perita, nam haec ars viros dedecet. (2.4. cap. 1, p. 447)

Por esta razão antes do parto deves escolher-se uma parteira previdente, instruída acerca das condições femininas e versada no exercício da obstetrícia, pois esta arte não convém aos homens.

De facto, a imperícia das parteiras é algo pernicioso: torna os rapazes eunucos (1.2. cap. 6, pp. 63-64), leva-as a cortar antes do momento certo o cordão umbilical (2.4. cap. 7, p. 478); está associada a superstiçóes absurdas (1.1. cap. 8, p. 32).. O mesmo afirmara Sorano, séculos antes. Se em toda a descrição de um partus naturalis é a parteira que age e toma decisôes, acompanhada, quando muito por "ajudantes com experiência e que deram à luz muitas vezes ou o próprio marido da mulher [i. e. da parturiente]"(ministrae peritae et quae saepius pepererunt aut ipse foeminae maritus (2.4. cap. 1, p. 448)), quando o parto se complica é o chirurgus quem desempenha as acções mais sensíveis, na presença do médico (accersitus chirurgus, praesente etiam medico).

Quanto mais desesperada fosse a situação, podemos afirmar, tanto mais pessoas que não a parteira seriam necessárias para desempenhar toda uma série de tarefas, das mais científicas às mais braçais: do médico que orientava, a homens ou mulheres da família, robustos o suficiente

41 Cf. Jean Le Bon, Therapia Puerperarum, in Gynaeciorum Libri, 1586, vol. 2, p. 387: Dilaniari enim non paucas gravidas mulieres a chirurgis, obstetricibus et tonsoribus, multosque semivivos infantulos ab iisdem dilacerari, saepius quam voluissemus, vidimus. Vimos, mais vezes do que teríamos desejado, serem dilaceradas não poucas mulheres grávidas por cirurgiões, parteiras e barbeiros, e muitas criancitas mal vivas serem desmembradas por estes.

42 Veja-se, por exemplo: (...) nec enim obstetrices permisimus unquam, manibus violentum aliquod tractarent, prout illis moris est, quando ex illa violenta attractione, multa vitia, et foedae affectiones oriuntur. (Cent. VI, cura 21) "(...) e não permitimos nunca que as parteiras usassem de algo violento com as mãos, conforme é o seu costume, visto que por causa dessa violenta actuação se originam muitos males e afecções desfeantes." Amato Lusitano, Centúrias..., vol. IV, op. cit., p. 33. Curabis tu, sapiens medice, ut obstetrices omni ingenio ac arte in hanc naturalem figuram, hoc est, in caput, foetum deducant (...) "Tu, médico sabedor, procurarás que as parteiras tirem o feto com o maior engenho e habilidade pela forma natural, isto é, pela cabeça (...)". Amato Lusitano, Centúrias..., vol. IV, op. cit., p. 84. 
para segurarem a parturiente e a sacudirem, passando pelo cirurgião que operava e pela parteira que fazia a versão do feto e examinava o corpo da paciente. É precisamente no meio desta multidão que sobressai o saber do médico, baseado nas autoridades antigas que como um alicerce fundamentam e legitimam práticas e terapêuticas.

\section{BIBLIOGRAFIA}

\section{Edições e Traduções}

Amato Lusitano, Curationum medicinalium Centuriae II. Priores. Lugduni, apud Guglielmum Rouillium, 1567. Amato Lusitano, Curationum medicinalium Centuriae Duae. Tertia et Quarta. Lugduni, apud Guglielmum Rouillium, 1565.

Amato Lusitano, Curationum medicinalium Centuriae Duae. Quinta et Sexta. Lugduni, apud Guglielmum Rouillium, 1576.

Amato Lusitano, Centúrias de curas medicinais, vol. I, II, III e IV (trad. Firmino Crespo). Lisboa, Universidade Nova de Lisboa, s. d.

Aristóteles, História dos Animais II (tradução de M. F. Sousa e Silva). Lisboa, Imprensa Nacional-Casa da Moeda, 2008.

Burguière P., Gourevitch, D. \& Malinas, Y., Soranos d'Éphèse I, II, III, IV. Paris, Les Belles Lettres, $2003^{2}$.

Castro, Rodrigo de, Philosophiae et Medicinae Doctoris De universa muliebrium morborum medicina, tertia editio auctior et emendatior. Hamburgi, ex Bibliopolio Frobbeniano, 1628.

Radicchi, R., La Gynaecia di Muscione: manuale per le ostetriche e le mamme del VI sec. d. C. Pisa, Giardini, 1970.

(Para os restantes textos usaram-se as edições do Thesaurus Linguae Graecae e do Packards Humanities Institute Latin Corpus)

\section{Estudos}

Burguière, P., "Histoire du Texte", in P. Burguière, D. Gourevitch \& Y. Malinas, Soranos d'Éphèse. Maladies des femmes I. Paris, Les Belles Lettres, 2003², pp. XLVII-LXV.

Dasen, V., "Multiple Births in Graeco-Roman Antiquity", Oxford Journal of Archaeology 16.1 (1997), pp. 49-63.

Daston, Lorraine \& PARK, Katherine, Wonders and the order of nature, 1150-1750. New York, Cambridge, Mass., Zone Books, 1998. 
Demand, Nancy, "Monuments, midwives and gynaecology", in Ph. J. van der Eijk, H. F. Horstmanshoff, \& P. H. Schrijvers, (eds.), Ancient medicine in its socio-cultural context. Amsterdam, Rodopi, 1992, pp. $275-290$.

Gourevitch, Danielle, "La gynécologie et l'obstétrique”, ANRW 37.3 (1996), pp. 2083-2146.

Gourevitch, Danielle, "La mort de la femme en couches et dans les suites de couches", in F. Hinard (ed.), La mort, les morts et l'au-delà dans le monde romain: Actes du Colloque de Caen, 20-22 novembre 1985. Caen, Centre de publications de l’Université de Caen, pp. 187-193.

Hanson, Ann E. \& Green, Monica H., "Soranus of Ephesus: Methodicorum princeps", ANRWII.37.2 (1994), pp. 968-1075.

Hanson, Ann E., "Continuity and change: Three Case Studies in Hippocratic Gynaecological Therapy and Theory", in Sarah Pomeroy (ed.), Women's History and Ancient History. Chapel Hill, University of North Carolina Press, 1991, pp. 73-110.

Hanson, Ann E., "A division of labor: roles for men in Greek and Roman births", Thamyris 1.2 (1994), pp. 157-202.

KInG, Helen, Hippocrates' woman: reading the female body in ancient Greece. London \& New York, Routledge, 1998.

KING, Helen, Midwifery, obstetrics and the rise of gynaecology: the uses of a sixteenth-century compendium. Aldershot, Hants \& Burlington, Ashgate Publishing, 2007.

Malinas, Yves, "Modernité de Soranos", in P. Burguière, D. Gourevitch \& Y. Malinas, Soranos d'Éphèse. Maladies des femmes I. Paris, Les Belles Lettres, 2003², pp. LXVII-LXXIV.

Stolberg, Michael, "A woman down to her bones: the anatomy of sexual difference in the sixteenth and early seventeenth centuries", Isis 94 (2003), pp. 274-299.

Von Staden, H., Herophilus: the art of medicine in early Alexandria. Cambridge-New York, Cambridge University Press, 1989. 
A partir dos alvores do século XVI, a matéria médica torna-se indiscutivelmente um tema de primeira grandeza entre os membros da República das Letras, objecto de estudo e de controvérsia entre os mais notáveis humanistas europeus, em particular entre os cultores da arte médica. Entre os autores em destaque neste volume encontram-se, à cabeça, os nomes de Amato Lusitano, Garcia de Orta e Nicolás Monardes, famosos pelos contributos valiosos que deram para o conhecimento do mundo natural. 0 volume encontra-se dividido em duas partes: a primeira, subordinada ao título "Humanismo e Ciência", alberga os estudos que versam sobre todos os autores estudados, à excepção de Amato Lusitano; a segunda está reservada a um conjunto de trabalhos dedicados exclusivamente ao médico albicastrense, cuja autoria se fica a dever, em boa parte, aos membros da equipa do projecto de I\&D "Dioscórides e o Humanismo Português: os Comentários de Amato Lusitano", tomando, por isso, 0 seu próprio título. Nesta segunda parte, oferece-se, desde já, aos leitores uma amostra significativa do trabalho desenvolvido no âmbito do projecto e que culminará, assim se espera, na edição e tradução integral para língua portuguesa das quatro obras previstas de Dioscórides, Amato Lusitano e Pietro Andrea Mattioli. 
